\title{
Sclerotherapy versus sclerotherapy and propranolol in the prevention of rebleeding from oesophageal varices: a randomised study
}

\author{
S S Elsayed, G Shiha, M Hamid, F M Farag, F Azzam, M Awad
}

\begin{abstract}
Background-This trial was carried out to assess the value of propranolol in the prevention of recurrent variceal bleeding when combined with longterm endoscopic sclerotherapy.

Patients and methods-Two hundred patients (161 male, 39 female, age range 20-68 years) with portal hypertension resulting mainly from schistosomal periportal fibrosis or posthepatitic cirrhosis presenting with their first episode of haematemesis or melena, or both were included. This was confirmed endoscopically to result from ruptured oesophageal varices. After initial control of bleeding, patients were randomised into two groups: group 1 treated with endoscopic sclerotherapy alone and group 2 treated with sclerotherapy plus propranolol. They were followed up for two years.

Results-Group (2) had a lower rebleeding rate $(14.3 \% v 38.6 \%$ in group 1$)$, lower variceal recurrence after obliteration $(17 \% v 34 \%$ in group 1$)$, longer period between variceal obliteration and recurrence (36 weeks $v 21$ weeks in group 1); but no change in mortality $(12 \%$ in both groups).

Conclusions-Patients treated with sclerotherapy should be given propranolol for longterm management.

(Gut 1996; 38: 770-774)
\end{abstract}

Keywords: propranolol, sclerotherapy, variceal rebleeding.

Bleeding from oesophageal varices is an important cause of morbidity and mortality in cirrhotic patients, ${ }^{1}$ as well as in patients with hepatosplenic schistosomiasis. ${ }^{2}$ Once a patient has bled from varices the risk of rebleeding is $70 \%$ or more. ${ }^{3}$ Endoscopic sclerotherapy is widely used for treatment of bleeding from ruptured oesophageal varices. ${ }^{4}$ Randomised controlled studies have shown that patients treated with sclerotherapy rebleed significantly less often than control patients treated conservatively. ${ }^{5-7}$ However, before variceal obliteration, sclerotherapy treated patients may experience a rebleeding rate as high as $50 \%{ }^{8}$

Propranolol has been shown to decrease portal pressure and to be more effective in preventing variceal rebleeding than placebo, ${ }^{10}$ although some studies have given conflicting results. ${ }^{11} 12$ Studies comparing a combination of sclerotherapy and propranolol versus sclerotherapy alone have given discordant results. ${ }^{13-15}$

The aim of this study was to compare endoscopic sclerotherapy alone with endoscopic sclerotherapy plus propranolol in patients with portal hypertension and variceal bleeding.

\section{Methods}

Inclusion criteria:

(1) First episode of upper gastrointestinal haemorrhage endoscopically confirmed to originate from oesophageal varices. Patients with gastric varices or ulcers were excluded from the study.

(2) No history of treatment with propranolol, or shunt surgery.

(3) No contraindications to $\beta$ blockers.

(4) No other serious disease that could affect the outcome of the study, for example, associated malignancy or renal failure.

Oesophageal varices were graded according to a previously published classification. ${ }^{15}$

Two hundred patients fulfilling the inclusion criteria presented at Al-Mansoura, Internal Medicine Department and were considered for the study from April 1991 until October 1991. After initial resuscitation, the bleeding episode was treated with balloon tamponade, vasopressin (Glypressin) and blood transfusion as required. All patients were then treated with endoscopic sclerotherapy. Twenty two patients were excluded from the study within the first day after admission (15 died and seven had a deteriorating course passing a hepatic precoma stage).

After resuscitation 178 patients were randomised into two groups using sealed opaque envelopes; group 1 was treated with endoscopic sclerotherapy alone (87 patients) and group 2 was treated with endoscopic sclerotherapy and propranolol (91) patients. All gave their informed consent to participate in the study. The patients were followed up for 17 to 24 months with a mean of 21 months. The study ended April 1993, 140 patients completed the study (70 in each group). Thirty three patients failed to comply to the sessions of sclerotherapy or oral propranolol therapy or did not attend the follow up despite reminders sent to their last known addresses. Five patients decided to have a shunt surgery.

\section{Sclerotherapy}

The free-hand technique was used with ethanolamine oleate $5 \%$ as the sclerosant. An intravariceal injection was given every two 


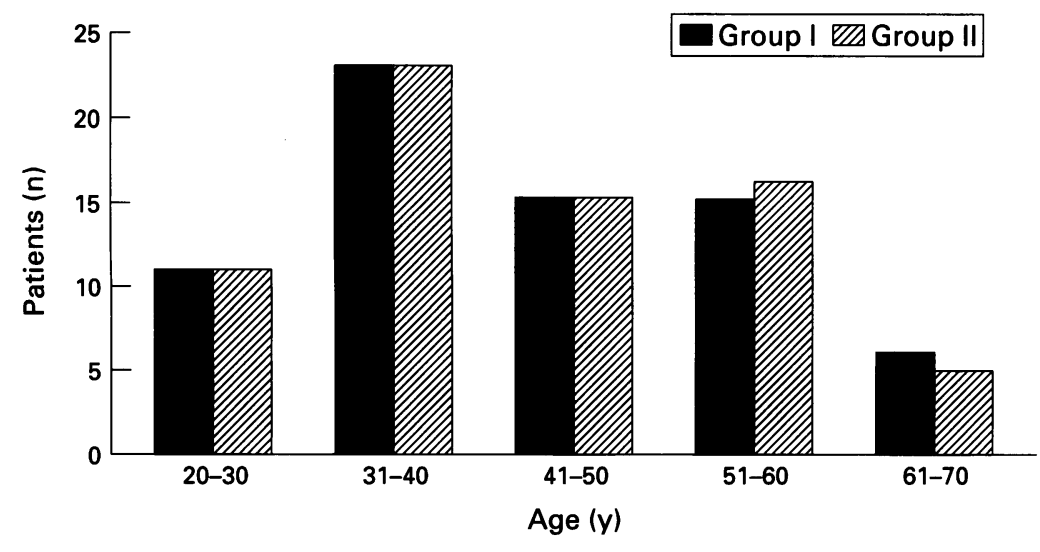

Figure 1: Age distribution in both groups.

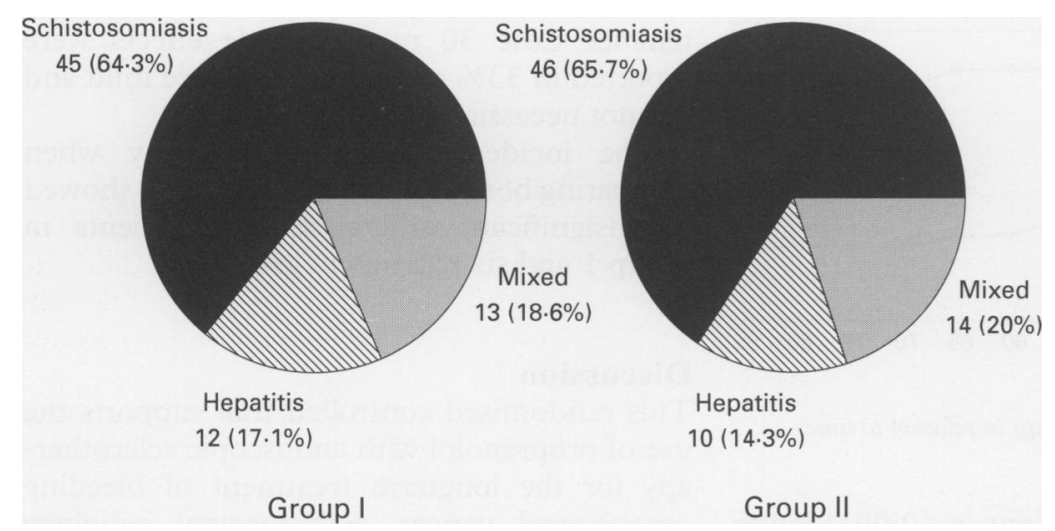

Figure 2: Aetiology of liver disease in treated patients.

weeks initially. Subsequent injections were according to the response until there was complete obliteration of the varices. There was a follow up every three months until the end of the study.

\section{Propranolol}

The dose was adjusted to reduce resting heart rate by $25 \%$. Treatment was started immediately after randomisation. Propranolol was discontinued in patients admitted with rebleeding.

\section{Rebleeding}

This was defined as any gastrointestinal haemorrhage requiring one or more blood units. Endoscopy was performed as soon as possible

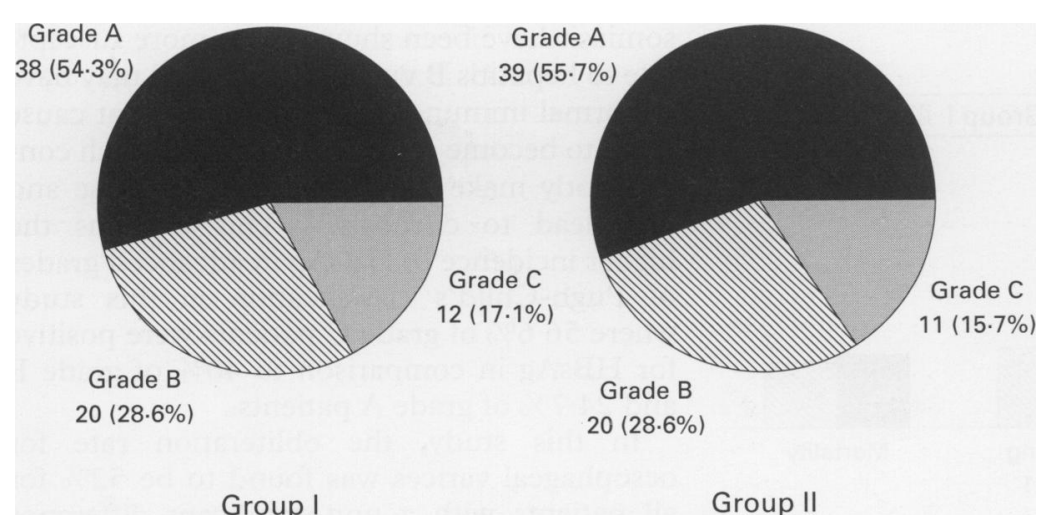

Figure 3: Severity of liver disease in treated patients according to Pugh's modification of Child's classification. after bleeding. A lesion was considered to be the cause of bleeding if presented with a clot on its surface, or it was seen actively bleeding, or no other lesion in the upper gastrointestinal tract could possibly have bled.

After the bleeding has been controlled, patients continued with the same treatment as previously.

\section{Statistical analysis}

Results are expressed as mean (SD). Comparisons were performed using the $\chi^{2}$ test, Student's $t$ test. Percentage of patients free from rebleeding in both groups in relation to time were estimated by the Kaplan-Meier method. ${ }^{16}$

\section{Results}

Initially, the two groups of patients were similar. The age range was 20-64 years with a mean of $43(12 \cdot 3)$ in group 1, 22-66 years with a mean of $43(12.5)$ in group 2 , and the peak incidence between 30-40 years in both groups (Fig 1). The female/male ratio was 12 of 58 in group 1 and 10 of 60 in group 2.

The aetiology of the underlying liver diseases was found to be schistosomal, 45 of 70 $(64.3 \%)$ in group 1 and 46 of $70(65.7 \%)$ in group 2, posthepatitic, 12 of $70(17 \cdot 1 \%)$ in group 1 and 10 of $70(14.3 \%)$ in group 2, and mixed cirrhosis, 13 of $70(18.6 \%)$ in group 1 and 14 of $70(20 \%)$ in group 2 (Fig 2).

Severity of liver disease according to Pugh's modification of Child's classification (Fig 3) was found to be: 38 of $70(54.3 \%)$ Child's A in group 1 and 39 of $70(55.7 \%)$ in group 2, 20 of $70(28.6 \%)$ Child's B in group 1 , and 20 of 70 $(28.6 \%)$ in group 2 and 12 of $70(17 \cdot 1 \%)$ Child's C in group 1, and 11 of $70(15.7 \%)$ in group 2.

Mean duration of the study was similar in both groups and ranged from 17 to 24 months with a mean of 21 months. Mean delay between acute sclerotherapy and randomisation was similar in both groups $(2.4(5.5) v 3$ (6) days for group 1 and 2 respectively).

Obliteration of oesophageal varices was achieved in $52 \%$ of patients with a non-significant difference between both groups. A mean time of 9.5 weeks was required in both groups, which corresponded to a mean of four sessions of sclerotherapy.

Variceal recurrence was recorded in $26 \%$ of patients, however, patients in group 2 showed a significantly lower recurrence rate, $17 \%$ in group $2 v 34 \%$ of group $1,(\mathrm{p}<0.05)$.

A significantly longer time after initial variceal obliteration to recurrence was recorded in group 2 (36 weeks) $v$ ( 21 weeks) in group $1,(\mathrm{p}<0.001)$.

The number of recurrent varices per patient was significantly lower in group $2(1 \cdot 8) v(2 \cdot 3)$ in group $1,(\mathrm{p}<0.05)$.

\section{Rebleeding}

The rebleeding rate was found to be $26.4 \%$ for all patients. When comparing both groups, 


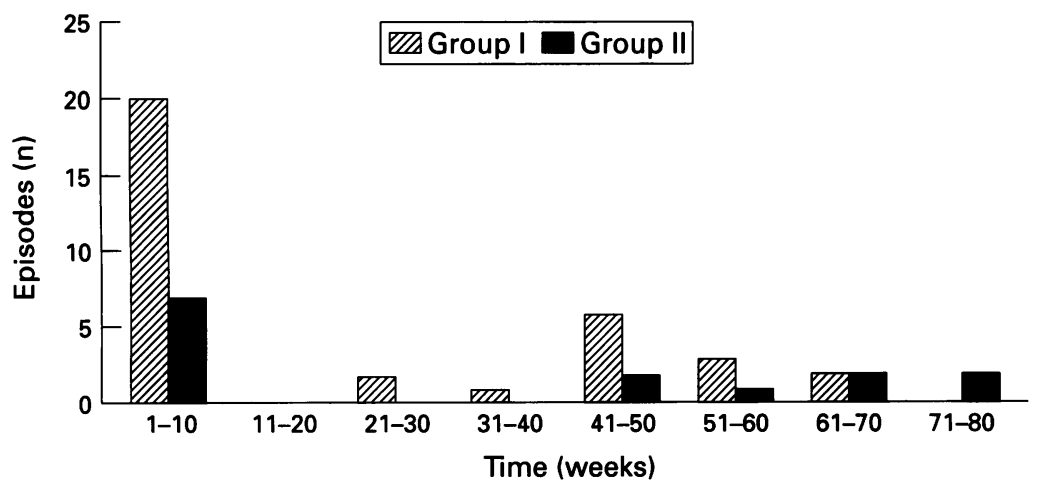

Figure 4: Number of rebleeding episodes in relation to time of follow up.

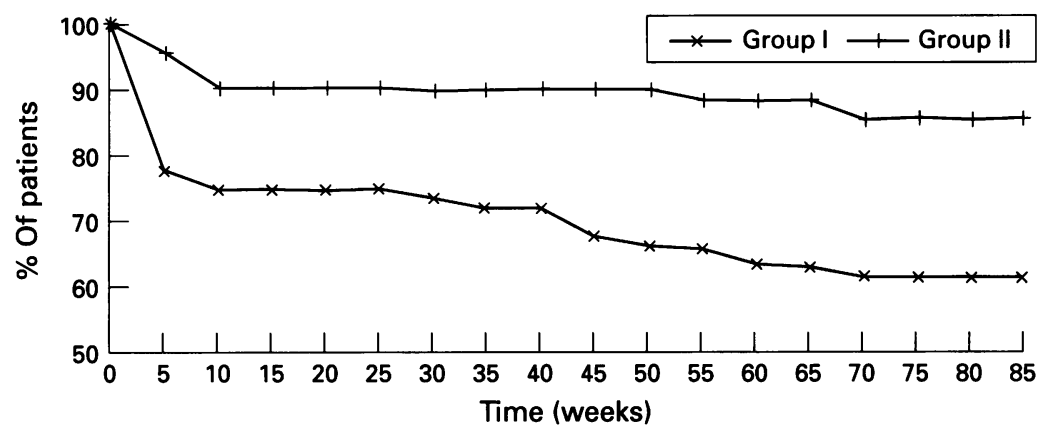

Figure 5: Percentage of patients free from rebleeding in both groups in relation to time.

there was a highly significant $(\mathrm{p}<0.001)$ lower rebleeding rate in group $2(14 \cdot 3 \%) v$ group 1 $(38.6 \%)$.

The number of rebleeding episodes in relation to time of follow up was recorded and the peak incidence was seen in the first 10 weeks in both groups (NS) (Figs 4 and 5).

The mean total blood requirement per patient was significantly lower in group $2(1.7$ $(3.7) v 2.9(6.7)$ units of blood in group 1 ; $\mathrm{p}<0.01)$.

\section{Mortality}

The death rate was found to be $12 \%$ for all patients, with non-significant difference between both groups (Fig 6).

\section{Complications of sclerotherapy}

Five patients in each group ( $7 \%$ of all patients) developed oesophageal strictures that responded well to dilatation using SavaaryGillard dilators.

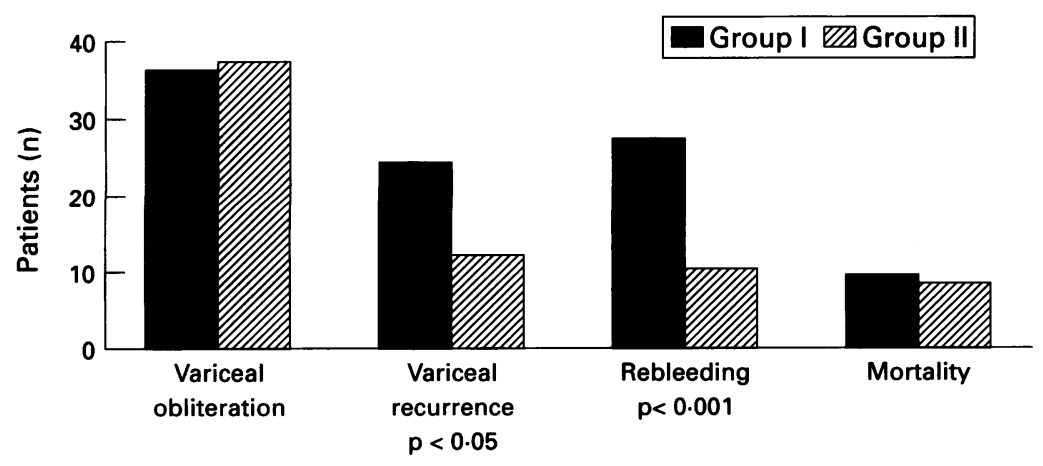

Figure 6: Rate of variceal obliteration, variceal recurrence, rebleeding, and mortality in both groups.
Pneumonia was recorded as the cause of death in two cases (one in each group) in whom emergency sclerotherapy was done.

Thirteen patients ( $9 \%$ of all patients) developed mild pleural effusion on $x$ ray and resolved completely.

Other minor side effects in the form of mild fever for one to two days, retrosternal discomfort or pain, and superficial oesophageal ulcerations at the injection sites were recorded and treated without affecting the final outcome.

\section{Propranolol therapy}

Propranolol was adjusted to decrease the resting heart rate by approximately $25 \%$. The mean initial daily dose was $90 \mathrm{mg}$ and maintenance dose $30 \mathrm{mg} /$ day. Side effects were reported in $33 \%$ of patients but were mild and did not necessitate stopping the drug.

The incidence of encephalopathy when comparing both groups after treatment showed an insignificant difference (five patients in group 1 and six patients in group 2).

\section{Discussion}

This randomised controlled trial supports the use of propranolol with endoscopic sclerotherapy for the longterm treatment of bleeding oesophageal varices. Schistosomal aetiology was predominant among the patients $(82.9 \%$ in group 1 and $85.7 \%$ in group 2) who, unlike patients with cirrhosis, have the advantage of a comparatively well preserved liver function, as the lesion is primarily a periportal fibrosis sparing the parenchyma until late advanced stage of the disease. ${ }^{17}$ This explains the higher rate of patients with Pugh-Child's grade A (55\%) in this study and also in the study of Cordiero et al where grade (A) patients represents $90 \%$ of their patients. ${ }^{2}$ In contrast, in studies comprising cirrhotic patients, grade (A) patients represent only $11 \cdot 4 \%$ and $13 \cdot 2 \%^{12}{ }^{13}$ respectively.

In this study, $17 \cdot 1 \%$ of patients in group 1 and $14.3 \%$ in group 2 were positive for HBsAg, which is very high in comparison to the prevalence of $\mathrm{HBsAg}$ among Egyptian healthy blood donors, which is $4 \% .{ }^{18}$ This could be explained by the fact that such a group of patients is at high risk of being exposed to repeated blood transfusion. Moreover patients with hepatosplenic schistosomiasis have been shown to be more susceptible to hepatitis B virus infection and may have abnormal immunological responses that cause them to become carriers of HBsAg, which consequently make their basic disease worse and may lead to cirrhosis. ${ }^{19}$ This explains the higher incidence of HBsAg in advanced grades of Pugh-Child's classification in this study where $56.6 \%$ of grade $C$ patients were positive for $\mathrm{HBsAg}$ in comparison to $40 \%$ of grade B and $24.7 \%$ of grade A patients.

In this study, the obliteration rate for oesophageal varices was found to be $52 \%$ for all patients with a non-significant difference between both groups. This obliteration rate is lower than that recorded by Vinel et al in 
France $(71 \%)$ after 14 weeks' follow up who also reported a non-significant difference between patients treated with sclerotherapy alone and those treated with sclerotherapy plus propranolol. ${ }^{15}$

The time needed to achieve obliteration of the varices was similar in both groups in this study with a mean of 9.5 weeks, which corresponds to a mean of four sessions of sclerotherapy in each group. These results are in accordance with those recorded by other investigators who showed that propranolol had no effect on obliteration rate and time when added to sclerotherapy. 131520

The main disadvantage of sclerotherapy is the eventual recurrence of varices in many patients. Terblanche et al mentioned that varices recur at a mean time of between one and two years after obliteration and that lifelong follow up and repeated injection of recurrent varices is essential to prevent rebleeding. ${ }^{21}$ Westaby et al reported that new varices had developed in $67 \%$ of patients with a median of 20 months follow up from the time of initial obliteration and most of these recurrences were seen within 12 months of the time of initial obliteration. ${ }^{22}$ Hashizome et al reported variceal recurrence in $46 \%$ after nine years follow up. 4

In this study, variceal recurrence was recorded in $26 \%$ of all patients after two years' follow up. Group 2 patients who were treated with propranolol plus sclerotherapy, however, showed a significant low recurrence rate $(17 \cdot 1 \%)$ in comparison to group 1 patients $(34 \%)(p<0.05)$. The delay between initial variceal obliteration and recurrence was longer in group 2 patients ( 36 weeks) in comparison to (21 weeks) in group $1(\mathrm{p}<0.001)$ and a significantly smaller number of recurrent varices per patient 1.8 in group $2 v 2.3$ in group 1 $(p<0.05)$. This shows that propranolol reduces the rate and delays the recurrence of varices and even decreases the number of recurrent varices per patient.

These results are in accordance with those of Jensen $^{23}$ who observed variceal recurrence in $15 \%$ of patients treated with propranolol plus sclerotherapy in comparison with $73 \%$ of patients treated with sclerotherapy alone after a follow up period of 18 months after initial variceal obliteration. They concluded that after variceal obliteration, sclerotherapy and propraonolol may be more effective in the longterm control of variceal recurrence than treatment with sclerotherapy alone.

Prevention or rebleeding from varices is the main goal of longterm sclerotherapy. The rebleeding rate differs from one study to another, however, depending upon aetiology and severity of liver disease, technique of sclerotherapy, sclerosant used, and duration of follow up. ${ }^{24}$

In this study the rebleeding rate in all patients was found to be $26.4 \%$ with a significantly lower rate $(13.3 \%)$ in group 2 when compared with group $1(38.6 \%)(\mathrm{p}<0.001)$.

These results are in agreement with other investigators. ${ }^{141525}$ On the other hand Vickers ${ }^{26}$ reported a non-significant difference between patients treated with sclerotherapy plus propranolol and those treated with sclerotherapy alone in terms of rebleeding after two years of follow up of 69 patients with cirrhosis. Also others ${ }^{1320}$ have reported that propranolol did not significantly reduce the frequency of rebleeding until variceal obliteration by sclerotherapy, these two studies comparing 41 and 53 cirrhotic patients respectively.

This difference in rebleeding rate between this study and those three studies could be explained by the fact that these studies included comparatively small number of patients with advanced liver cirrhosis and the causes of rebleeding in most cases were attributed to mucosal ulcerations and to congestive gastropathy whereas in our study variceal bleeding was considered the main cause of rebleeding. Actual bleeding from non-variceal sites was extremely uncommon in our patients, which is similar to the findings of other studies by Vinel ${ }^{15}$ and Westaby. ${ }^{27}$

In this study rebleeding was significantly higher in patients with grade C Pugh-Child's classification, when compared with grade B or grade A patients of the same group. This is in agreement with Garrett, ${ }^{8}$ and Balanzo. ${ }^{28}$

Although the combination of propranolol and sclerotherapy was found to be superior to sclerotherapy alone in prevention of rebleeding, it does not affect the death rate. Seventeen patients died ( $12 \%$ of patients included) with a non-significant difference between both groups. These results are in agreement with many studies. 14152527

The mean initial daily dose of propranolol in this study was $90 \mathrm{mg}$ and the mean maintenance does was $30 \mathrm{mg} / \mathrm{day}$. This resulted in reduction of resting heart rate by about $25 \%$. These doses are generally smaller than those of other studies where the mean daily dose was $105 \mathrm{mg},{ }^{15} 54 \mathrm{mg},{ }^{29} 120 \mathrm{mg},{ }^{13} 2771 \mathrm{mg},{ }^{30}$ and $160 \mathrm{mg}^{25}$

This could be explained by the fact that propranolol has a wide variation in its bioavailability, which varies according to the severity and aetiology of liver disease ${ }^{31}$ and by changes in its absorption. ${ }^{32}$

Propranolol in this study was well tolerated and the side effects were minimal. Moreover there was no significant difference in hepatic encephalopathy when comparing both groups despite previous reports that implicated propranolol in the precipitation of encephalopathy. ${ }^{27} 33$ Also other studies reported a higher incidence of hepatic encephalopathy in a placebo group than in patients treated with propranolol. ${ }^{34} 35$

In conclusion this study provides support for the longterm use of propranolol plus endoscopic sclerotherapy for the prevention of rebleeding from oesophageal varices although the overall death rate is not affected.

\footnotetext{
Graham DY, Smith JL. The course of patients after variceal haemorrhage. Gastroenterology 1981; 80: 800-9.

Cordeiro F. Variceal sclerosis in schistosomatic patients, a 5-years follow-up. Gastrointest Endosc 1990; 36: 475-8. 5-years follow-up. Gastrointest Endosc 1990; 36: 475-8.
DeDombal FT, Clarke JR, Clamp SE, Malizia G, Kotwal DeDombal FT, Clarke JR, Clamp SE, Malizia G, Kotwal
MR, Morgan AG, et al. Prognostic factors in upper gastrointestinal bleeding. Endoscopy 1986; 18 (suppl 2): 6-10. 4 Hashizume M, Kitano S, Koyangi N, Tanoue K, Ohta M, Wad H, et al. Endoscopic injection sclerotherapy for 1000
} 
patients with oesophageal varices. A nine-year prospective study. Hepatology 1992; 15: 69-75.

5 Terblanche J, Bornman PC, Kahn D, Jonker MA, Campbell JAH, Wright J, et al. Failure of repeated injection sclerotherapy to improve long-term survival after oesophageal variceal bleeding. A 5-years controlled trial. Lancet 1983; ii: $1328-32$.

6 Yassin YM, Sherif SM. Randomized controlled trial of injection sclerotherapy for bleeding oesophageal varices. Brf Surg 1983; 70: 20-2.

7 Korula J, Balart LA, Radvan G, Zweiban BE, Larson AW, Kao HW, et al. A prospective randomized controlled trial of chronic oesophageal variceal sclerotherapy. Hepatology of chronic oesophar

8 Garrett KO, Reilly Jr, Schade RR, Van Thiel DH. Sclerotherapy of oesophageal varices, long-term results and determinants of survival. Surgery 1988; 104: 819-23.

9 Lebrec D, Corbic M, Nouel O, Benhamon JP. Propranolol - a medical treatment for portal hypertension. Lancet 1980; ii: 180-2.

10 Lebrec D, Poynard T, Hillon P, Benhamon JP. Propranolol in gastrointestinal bleeding in cirrhosis. $N \mathrm{Engl} \mathrm{f} \mathrm{Med}$ 1982; 306: 1551 .

11 Burroughs AK, Jenkins WJs, Sherlock S, Dunk A, Walt RP, Osuaporo $\mathrm{T}$, et al. Controlled trials of propranolol for the prevention of recurrent variceal haemorrhage in patients prevention of recurrent variceal haemorrhage in pat
with cirrhosis. $N$ Engl $₹$ Med 1983; 309: 1539-42.

12 Villeneuve JP, Pomier G, Infante-Rivard C, Willems B, Huet PM, Marlean D, et al. Propranolol for the prevention of recurrent variceal bleeding. A controlled trial Hepatology 1986; 6: 1239-43.

13 Westaby D, Melia W, Hegarty J, Gimson AES, Stellon AJ, Williams $R$, et al. Use of propranolol to reduce the rebleeding rate during injection sclerotherapy prior to variceal obliteration. Hepatology 1986; 6: 673-5.

14 Kanazawa H, Watari A, Matsusaka S, Tada N, Miyata K, Saitch H, et al. Prospective controlled study of elective sclerotherapy plus oral propranolol for prevention of sclerotherapy plus oral propranolol for prevention of orrhage (English abstract). Nippon Shokakibyo Gakkai Zashi 1991; 88: 1341-8.

15 Vinel JP, Lamouliatte H, Cales P, Combis JM, Roux D, Desmorat $\mathrm{H}$, et al. Propranolol reduces the rebleeding rate during endoscopic sclerotherapy. A randomized study. Gastroenterology 1990; 98 (A): 644

16 Kaplan EL, Meier J. Fournal of the American Statistical Association 1958; 53: 457-82.

17 Ramos OL, Saad F, Lesser WP. Portal haemodynamics and liver cell function in hepatic schistosomiasis. Gastroenterology 1964; 47: 241-7.

18 Abd El Raouf L. Pattern of some viral antibodies in transfused patients [thesis]. Mansoura Faculty of Medicine, Egypt, 1991.

19 Lyra LG, Reboucas G, Andrad ZA. Hepatitis B surface antigen carrier state in hepatosplenic schistosomiasis.
Gastroenterology 1976; 71: 641-5.

20 Lundell L, Leth R, Lind T, Lonroth H, Sjovall M, Olbe L. Evaluation of propranolol for prevention of recurrent bleeding from oesophageal varices between sclerotherapy sessions. Acta Chir Scand 1990; 156: 711-5.

21 Terblanche J. The surgeon role in management of portal hypertension. Ann Surg 1989; 209: 381-95.

22 Westaby D, William R. Follow-up study after sclerotherapy. Scand f Gastroenterol 1984; 19: 71-4.

23 Jensen IS, Krarup N. Propranolol may prevent recurrence of oesophageal varices after obliteration by endoscopic of oesophageal varices after obliteration by endoscop
sclerotherapy. Scand $₹$ Gastroenterol 1990; 25: 352-6.

24 Binmoeller H, Grimm H, Soehendra N. Treatment of oesophageal varices. Endoscopy 1992; 24: 52-7.

25 Jensen LS, Krarup N. Propranolol in prevention of rebleeding from oesophageal varies during the course of endoscopic sclerotherapy. Scand $\mathcal{f}$ Gastroenterol 1989; 24: 339-45.

26 Vickers C, Rhodes J, Hillinbrand P, Bradby H, Hawker P, Dykes $\mathrm{P}$, et al. Prospective controlled trial of propranolol and sclerotherapy for prevention of rebleeding from oesophageal varices. Gut 1987; 28: A1359.

27 Westaby D, Polson RJ, Gimson AE, Hayes PC, Hayllar J, Williams R. A controlled trial of oral propranolol compared with injection sclerotherapy for the long-term pared with injection sclerotherapy for the long-term managem.

28 Balanzo J, Such J, Sainz S. Long-term survival and severe rebleeding after variceal sclerotherapy. Surg Gynecol Obstet 1990; 171: 489-92.

29 Rossi V, Cales P, Burtin P, Charneau J, Person B, Pujol P, Valentin S. Prevention of recurrent variceal bleeding in alcoholic-cirrhotic patients. Prospective controlled trial of propranolol and sclerotherapy. $\mathcal{F}$ Hepatol 1991; 12: 283-9.

30 O'Connor KW, Lehman G, Yune H, Brunelle R, Christiansen P, Hast J, et al. Comparison of three nonsurgical treatments for bleeding esophageal varices. surgical treatments for bleeding

31 Routledge PA, Shand DG. Clinical pharmacokinetic of propranolol. Clin Pharmacokinet 1979; 4: 73-90.

32 Wood AJ, Kornhauser DM, Wilkinson DG, Shand DG, Branch RA. The influence of cirrhosis on steady state blood concentrations of unbound propranolol after oral administration. Clin Pharmacokinet 1978; 3: 478-87.

33 Tarver D, Walt PR, Dunk AA, Jenkins WJ, Sherlock S. Precipitation of hepatic encephalopathy by propranolol in cirrhosis. BMf 1983; 287: 585.

34 Hayes PC, Crichton S, Shepherd AN, Bouchier IAD. Propranolol in chronic liver disease: a controlled trial of its effect and safety over twelve months. $Q \Im$ Med 1987; 246: 823-34.

35 Italian Multicenter Project for Propranolol in Prevention of Bleeding. Propranolol for prophylaxis of bleeding in cirrhotic patients with large varices. A multicenters randomized clinical trial. Hepatology 1989; 8: 1-5. 